Jurnal Penelitian Pendidikan Geografi Volume 4 No.2 April 2019

\title{
DESKRIPSI MATA PENCAHARIAN MASYARAKAT DAN TINGKAT KESEJAHTERAAN MASYARAKAT DI DESA LAGASA KECAMATAN DURUKA KABUPATEN MUNA
}

\author{
Siti Supmawati' Ramli $^{2}$ \\ ${ }^{1}$ Alumni Pendidikaan Geografi Universitas Halu Oleo \\ ${ }^{2}$ Dosen pendidikan geografi Universitas Halu Oleo
}

\begin{abstract}
Abstrak: Masalah yang diajukan dalam penelitian ini yaitu Bagaimana gambaran mata pencaharian masyarakat dan tingkat kesejahteeaan masyarakat di Desa Lagasa Kecamatan Duruka Kabupaten Muna. Penelitian ini bertujuan untuk mengetahui gambaran mata pencaharian masyarakat dan tingkat kesejahteraan masyarakat. Penelitian ini dilakukan di Desa Lagasa Kecamatan Duruka Kabupaten Muna dengan jumlah sampel sebanyak 46 informan. Metode penelitian menggunakan metode kualitatif. Peneliti mengambil data dengan teknik wawancara dan dokumentasi. Pemilihan sampel dengan menggunakan teknik simple random sampling yaitu pengambilan sampel anggota populasi dilakukan secara acak tanpa memperhatikan strata yang ada dalam populasi itu. Hasil penelitian ini menunjukkan bahwa berdasarkan mata pencaharian terhadap 46 responden maka diperoleh data bahwa jumlah responden mata pencaharian yang ada di Desa Lagasa yang tertinggi adalah mata pencaharian sebagai Nelayan sebanyak 24 responden atau sebesar 52\%, dikarenakan posisi mereka pada umumnya tingggal dipinggir pantai, sebuah lingkungan permukiman yang dekat dengan lokasi kegiatannya, dimana mereka bisa tergantung langsung pada hasil laut, baik dengan cara melakukan penangkapan ikan, mereka memili bekerja sebagai masyarakat nelayan sudah sejak dahhulu bahkan pekerjaan ini adalah pekerjaan pokok didesa Lagasa. Dan berdasarkan indikator kesejahteraan masyarakat di Desa Lagasa Kecamatan Duruka berada pada tingkat kesejahteraan sedang, dengan jumlah skor 15, dilahat dari 7 indikator kesejahteraan masyarakat.
\end{abstract}

Kata Kunci : Mata Pencaharian, Proses, Tingkat Kesejahteraan Masyarakat 
Jurnal Penelitian Pendidikan Geografi Volume 4 No.2 April 2019

\title{
DESCRIPTION OF COMMUNITY LIVELIHOODS AND LEVEL OF WELFARE OF THE COMMUNITY IN THE VILLAGE LAGASA KECAMATAN DURUKA MUNA DISTRICT
}

\author{
Siti Supmawati', Ramli ${ }^{2}$ \\ ${ }^{1}$ Geography Educational Alumni Halu Oleo University \\ ${ }^{2}$ Geography education lecturer at Halu Oleo University
}

\begin{abstract}
The problem proposed in this study is how is the description of people's livelihoods and the level of welfare of the community in the village Lagasa Kecamatan Duruka Muna district. This study aims to determine the description of people's livelihoods and the level of community welfare. This research was conducted in the village Lagasa Kecamatan Duruka Muna district, with the number of samples as many as 63 informants. The research method uses qualitative methods. The researcher took the data with interview techniques and documentation. sample selection using the stratified random sampling technique, which is a sample drawn by separating population elements in groups of non-overlapping pliers called strata, and then selecting a sample randomly from each stratum. The results of this study indicate that based on livelihoods of 63 respondents, data obtained that the highest number of livelihood respondents in the village Lagasa were as many as 57 respondents as fishermen's livelihoods or $90 \%$, due to their position generally living on the shore, a residential environment which is close to the location of their activities, where they can depend directly on marine products, either by doing fishing, they have chosen to work as fishing communities since long ago and even this work is the main job in the village Lagasa. And based on the welfare indicators of the people in the village Lagasa Kecamatan Duruka based on the people who are at the level of prosperity, safety, and prosperous family I.
\end{abstract}

Key words: livelihood, process, level of community welfare

\section{PENDAHULUAN}

Kehidupan

dalam

bermasyarakat dapat kita amati adanya pola-pola hidup dari suatu masyarakat yang beraneka ragam, mulai dari keorganisasian masyarakat, upacara, adat istiadat, pendidikan, mata pencaharian dan berbagai hal yang menyangkut keberagaman hidup yang berlaku dalam suatu masyarakat. Polapola tersebut sangatlah penting dan memiliki arti tersendiri di dalam sebuah kehidupan, salah satunya mata pencaharian yang merupakan sumber perekonomian dan kesejahteraan sosial suatu keluarga dalam masyarakat. Mata pencaharian suatu masyarakat memiliki banyak ragam yang tersebar di berbagai daerah seperti pertanian, perdagangan, perindustrian, perkebunan, nelayan, buruh, perkantoran dan lain-lain yang disesuaikan dengan keadaan geografis daerahnya. Mereka melakukannya dengan tujuan untuk memenuhi kebutuhan hidup (ekonomi) dan kesejahteraan keluarga mereka, contohnya pada masyarakat pesisir pantai, mayoritas mata pencaharian mereka adalah nelayan. Mata 
pencaharian tersebut dapat berjalan dengan baik hal ini dikarenakan keadaan geografis wilayah tempat mereka tinggal yaitu pesisir sangat mendukungnya. Begitu pula untuk mata pencaharian masyarakat lainnya yang mengikuti keadaan geografis wilayah mereka tinggal (Abdurracmat, I (1984).

Mata pencaharian adalah pekerjaan pokok yang dilakukan oleh manusia untuk hidup dan sumber daya yang tersedia untuk membangun kehidupan yang memuaskan (peningkatan taraf hidup), dengan memperhatikan faktor seperti mengawasi penggunaan sumber daya, lembaga dan hubungan politik. Dalam perkembangannya, mata pencaharian seseorang sering kali berubah baik karena faktor internal, eksternal, ataupun kombinasi dari keduanya ( Wahyu, 2007 ).

Kesejahteraan merupakan tujuan dari seluruh keluarga. Kesejahteraan diartikan sebagai kemapuan keluarga untuk memenuhi semua kebetuhan untuk bisa hidup layak, sehat dan produktif. Berdasarkan data BPS ( 2009), masih terdapat sekitar 31 juta orang atau $13,3 \%$ penduduk yang tinggal dibawah garis kemiskinan atau mereka yang tidak memiliki untuk memenuhi semua kebutuhan pokoknya. Penduduk miskin sebagaian besar tinggal di wilayah pedesaan yang erat kaitannya dengan usaha pertanian. Tingkat penghasilan/ pendapatan seseorang akan berpengaruh besar terhadap ketenangan atau kesejahteraan, orang bisa menjadi tidak sejahtera dalam rumah tangganya karena tidak tenang jiwanya dalam menyesuaikan diri (Anwar,2009).

Dalam memahami realitas tingkat kesejahteraan, pada dasarnya terdapat beberapa faktro yang menyebabkan terjadinya kesenjangan tingkat kesejahteraan antara lain : 1). Sosial ekonomi rumah tangga atau masyarakat, 2). Struktur kegiatan ekonomi sektoral yang menjadi dasar kegiatan produksi rumah tangga atau masyarakat, 3). Potensi regional ( sumberdaya alam, lingkungan dan infrastruktur) yang memperngaruhi perkembangan struktur kegiatan produksi, dan 4). Kondisi kelembagaan yang membentuk jaringan kerja produksi dan pemasaran pada skala local, regional dan global (Acheson, 1981).

Berdasarkan data dari BPS jumlah penduduk di desa lagasa sebanyak 2.939 jiwa,dengan kepadatan penduduk sebesar $2.578 \mathrm{jiwa} / \mathrm{km} 2$, dengan jumlah kepala keluarga sebnyak 616 jiwa. Desa lagasa kecamatan duruka kabaupaten muna sebagaian besar menggantungkan kehidupan mereka terhadap hasil laut di mana masyarakatnya bekerja sebagai nelayan.

Bagi masyarakat yang bekerja ditengah-tengah lautan, lingkungan fisik laut sangatlah mengundang banyak bahaya, karena pekerjaan nelayan adalah memburu Ikan dan hasilnya tidak dapat ditentukan kapasitasnya semuanya hampir serba spekulatif.

Berdasarkan uraian diatas maka peneliti melakukan penelitian berjudul "Deskripsi Mata Pencaharian Masyarakat Dan Tingkat Kesejahteraan Masyarakat Di Desa Lagasa Kecamatan Duruka Kabupaten Muna.

\section{METODE PENELITIAN}

Populasi dalam penelitian ini adalah seluruh masyarakat Desa Lagasa Kabupaten Muna yang berjumlah 616 KK. Informan dalam penelitian ini adalah $10,2 \%$ dari jumlah populasi yaitu $63 \mathrm{KK}$ 
yang diambil secara Stratifed Random Sampling.

Variabel yang digunakan dalam penelitian ini adalah tingkat kesejahteraan menurut BKKBN, 2014 dan masyarakat di Desa Lagasa Kabupataen Muna.

$\begin{array}{lr}\text { a. Tingkat } & \text { Kesejahteraan } \\ \text { merupakan tingkatan } & \text { yang } \\ \text { menyatakan kemampuan dalam } \\ \text { memenuhi kebutuhan hidup spiritual } \\ \text { dan materil yang layak, bertaqwa } \\ \text { kepada Tuhan yang Maha Esa, } \\ \text { memiliki hubungan yang serasi, } \\ \text { selaras dan seimbang antara } \\ \text { keluarga, masyarakat dan } \\ \text { lingkungan. Indikator } \\ \text { tingkat kesejahteraan dilihat dari } \\ \text { tahapan - tahapan tingkat } \\ \text { kesejahteraan yang dibuat oleh } \\ \text { BKKBN (2014). }\end{array}$

Teknik pengumpulan data yang digunakan dalam penelitian ini adalah:

1. Teknik Wawancara, dengan alat yang digunakan berupa daftar wawancara dengan menggunakan pernyataan secara lisan kepada responden sehingga dapat memberikan informasi yang tepat tentang objek yang diteliti.

2. Observasi

Observasi dilakukan oleh peneliti untuk mengumpulkan data yang sesuai dengan sifat penelitian karena mengadakan pengamatan secaralangsung atau disebut pengamatan terlibat dimana peneliti juga menjadi instrumen atau alat dalam penelitian sehingga peneliti harus mencari data sendiri dengan terjun langsung atau mengamati dan mencari langsung ke beberapa informan yang telah ditentukan sebagai sumber data. Metode observasi ini, peneliti memilih jenis observasi partisipatif adalah observasi yang sekaligus melibatkan diri selaku orang dalam pada situasi tertentu. Hal ini agar memudahkan peneliti memperoleh data atau informasi dengan mudah dan leluasa.

3. Studi Dokumenter, alat yang digunakan dalam studi dokumenter adalah studi dokumentasi pada instansi terkait seperti BKKBN, BPS, dan kantor Kepala desa Dahari Selebar.

Teknik analisis data yang digunakan dalam penelitian ini adalah dengan menggunakan analisis deskriptif kualitatif. Dalam teknik analisis data ini dibantu dengan

1. Editing

Pada tahap ini di lakukan dengan memperhatikan kelengkapan daftar koesioner, tujuannya agar data yang di peroleh merupakan informasi yang benar, lengkap, jelas, relevan dan konsisten.

2. Coding

Pengkodean di maksudkan untuk merubah data yang berbentuk huruf menjadi angka dengan tujuan agar mudah mengolah dan menganalisis data dengan memberi kode dalam bentuk angka.

3. Tabulating

Pada tahap ini dilakukan pembuatan master tabel dan pemindahan hasil koding ke daftar koding. 
HASIL PENELITIAN

Responden Berdasarkan Umur
Apabila di lihat dari segi umur, masyarakat desa lagasa yang di jadikan sebagai responden dapat di lihat dari tabel sebagai berikut :

Tabel 3.1 Klasifikasi Umur Responden

\begin{tabular}{cccc}
\hline No & Umur (tahun) & Jumlah & Persentase \% \\
\hline 1. & $20-29$ & 2 & $3,2 \%$ \\
\hline 2. & $30-39$ & 20 & $31,7 \%$ \\
\hline 3. & $40-49$ & 21 & $33,33 \%$ \\
\hline 4. & $50-59$ & 16 & $25,4 \%$ \\
\hline 5. & $>60$ & 4 & $6,34 \%$ \\
\hline & Total & 63 & $100 \%$ \\
\hline
\end{tabular}

Sumber : Data Diolah (2018)

Kelompok umur responden

paling besar adalah pada kelompok umur 40-49 tahun sebanyak 21 responden $(33,33 \%)$ dan kelompok umur responden paling kecil kelompok umur 20-29 tahun (3,2\%).
Responden Berdasarkan Tingkat Pendidikan

Untuk mengetahui tingkat pendidikan responden akan di gambarkan dalam tabel berikut ini :

Tabel 3.2 Klasifikasi Pendidikan Responden

\begin{tabular}{llcc}
\hline No & Pendidikan & $\mathbf{2}$ & Desa \\
\cline { 3 - 4 } & & 5 & Persentase \% \\
\hline 1. & Tidak Tamat SD & 28 & $8 \%$ \\
\hline 2. & Tamat SD & 23 & $44,4 \%$ \\
\hline 3. & Tamat SMP & 6 & $36,5 \%$ \\
\hline 4. & Tamat SMA & 1 & $9,5 \%$ \\
\hline 5. & PT & 63 & $1,6 \%$ \\
\hline \multicolumn{2}{r}{ Total } &
\end{tabular}

Sumber : Data Diolah (2018)

Dari tabel diatas menunjukan bahwa responden masyarakat di Desa Lagasa yang mayoritas memliki tingkat pendidikan yang relatif rendah. Dimana dari 63 responden, masyarakat di Desa Lagasa yang tidak tamat SD sebanyak 5 orang dengan persentase $8 \%$, dan yang tamat SD sebanyak 28 orang dengan persentase $44,4 \%$, yang tamat SMP sebanyak 23 orang

dengan persentase $36,5 \%$, yang tamat SMA berjumlah 6 orang dengan persentase 9,5\%, dan yang tamat perguruan tinggi berjumlah 1 orang dengan persentase $1,6 \%$.

\section{Hasil Deskripsi Mata Pencahrian}

Berdasarkan hasil penelitian terhadap 63 responden maka diperoleh data distribusi responden berdasarkan mata pencaharian responden dapat dilihat pada tabel berikut 
Jurnal Penelitian Pendidikan Geografi Volume 4 No.2 April 2019

Tabel 3.3 Data Mata Pencaharian

\begin{tabular}{llcc}
\hline \multirow{2}{*}{ No } & Mata Pencaharian & \multicolumn{2}{c}{ Desa Lagasa } \\
\cline { 3 - 4 } & & $\mathbf{N}$ & Persentase \% \\
\hline 1. & Nelayan & 57 & $90,5 \%$ \\
\hline 2. & PNS & 1 & $1,6 \%$ \\
\hline 3. & Penambang & 1 & $1,6 \%$ \\
\hline 4. & Lain-lain & 4 & $6,3 \%$ \\
\hline \multicolumn{2}{r}{ Total } & 63 & $100 \%$ \\
\hline
\end{tabular}

Sumber : Data Diolah (2018)

Dari tabel diatas terlihat bahwa jumlah responden yang memiliki mata pencaharian sebagai nelayan sebanyak 57 orang dengan persentase 90,5\%, dan yang memiliki mata pencaharian sebagai PNS berjumlah 1 orang dengan persentase $1,6 \%$, mata pencaharian sebagai penambang berjumlah 1 orang dengan persentase $1,6 \%$, mata pencaharian lain-lain berjumlah 4 orang dengan persentase $6,3 \%$.

\begin{abstract}
Hasil Deskripsi Tingkat Kesejahteraan Masyarakat Desa Lagasa

Penelitian ini menganalisis tingkat kesejahteraan keluarga di desa Lagasa berdasarkan tahapan kesejahteraan yang dikembangkan oleh BKKBN. Terdiri dari 21 indikator dan dibagi menjadi 5 tahapan yaitu Keluarga Pra Sejahtera, Keluarga Sejahtera Tahap I (KS I), Keluarga Sejahtera Tahap II (KS II), Keluarga Sejahtera Tahap III (KS III), dan Keluarga Sejahtera Tahap III Plus (KS III+). Adapun tingkat kesejahteraan kelaurga masyarakat di Desa Lagasa adalah sebagai berikut.
\end{abstract}

Tabel 3.4 Tingkat Kesejahteraan Keluarga Desa Lagasa

\begin{tabular}{llcc}
\hline No & Tingkat Kesejahteraan & Jumlah (Keluarga) & Persentase \\
\hline 1 & Prasejahtera & 52 & $82,5 \%$ \\
\hline 2 & KS I & 11 & $17,5 \%$ \\
\hline Jumlah & $\mathbf{6 3}$ & $\mathbf{1 0 0 \%}$
\end{tabular}

Sumber : Data primer yang diolah, (2018)

Dari tabel dapat diketahui bahwa tingkat kesejahteraan keluarga pada masyarakat di Desa Lagasa masih berkisar pada tahapan Prasejahtera sampai KS I. Dari tabel tersebut persentase terbanyak terdapat pada keluarga yang termasuk dalam keluarga prasejahtera yaitu $82,5 \%$ dengan mencapai 52 Keluarga, sementara keluarga sejahtera tahap I (KS I) yaitu sebanyak 11 keluarga dengan persentase $17,5 \%$. 


\section{Hasil Deskripsi Tingkat Kesejahteraan Masyarakat Berdasarkan Mata Pencaharian}

1. Tingkat Masyarakat Nelayan
Kesejahteraan

\begin{abstract}
Berdasarkan hasil penelitian terhadap 63 responden maka diperoleh data distribusi responden berdasarkan indikator tingkat kesejahteraan masyarakat nelayan yang dapat dilihat sebagai berikut:
\end{abstract}

Tabel 3.5. Tabel Tingkat Kesejahteraan Masyarakat Dengan Mata Pencaharian Sebagai Nelayan

\begin{tabular}{|c|c|c|c|}
\hline No & Tingkat Kesejahteraan & Jumlah & Persentase (\%) \\
\hline 1. & Prasejahtera & 49 & $86 \%$ \\
\hline 2. & KS I & 8 & $14 \%$ \\
\hline & Total & 57 & $100 \%$ \\
\hline
\end{tabular}

\section{Sumber : Data diolah 2018}

Dari tabel di atas dapat diketahui bahwa tingkat kesejahteraan masyarakat nelayan di Desa Lagasa masih berkisar pada tahapan Prasejahtera sampai KS I. Dari tabel tersebut jumlah masyarakat yang tergolong masyarakat Prasejahtera berjumlah 49 orang dengan persentase $86 \%$, sementara keluarga sejahtera tahap I (KS1) yaitu

Tabel 3.6 Tingkat Kesejahteraan Masyarakat Dengan Mata Pencahrian

berjumlah 8 orang dengan persentase $14 \%$.

2. Tingkat Kesejahteraan Masyarakat PNS

Berdasarkan hasil penelitian terhadap 63 responden maka diperoleh data distribusi responden berdasarkan indikator tingkat kesejahteraan masyarakat PNS yang dapat dilihat sebagai berikut: Sebagai PNS

\begin{tabular}{cccc}
\hline No & Tingkat Kesejahteraan & Jumlah & $\begin{array}{c}\text { Persentase } \\
(\%)\end{array}$ \\
\hline 1. & KS I & & 1 \\
\hline & Total & 1 & $100 \%$ \\
\hline
\end{tabular}

Sumber : Data Diolah 2018

\begin{tabular}{|c|c|}
\hline \multirow{8}{*}{$\begin{array}{l}\text { Dari tabel di atas dapat } \\
\text { diketahui bahwa tingkat } \\
\text { kesejahteraan masyarakat PNS di } \\
\text { Desa Lagasa masih berkisar pada } \\
\text { tahapan KS I . Dari tabel tersebut } \\
\text { jumlah masyarakat yang tergolong } \\
\text { masyarakat keluarga sejahtera tahap } \\
\text { I (KS 1) yaitu berjumlah } 1 \text { orang } \\
\text { dengan persentase } 100 \% \text {. }\end{array}$} & 3. Tingkat \\
\hline & Masyarakat Penambang \\
\hline & Berdasarkan hasil peneliti \\
\hline & responden \\
\hline & diperoleh data distribusi respo \\
\hline & indikator \\
\hline & kesejahteraan \\
\hline & $\begin{array}{l}\text { penambang yang } \\
\text { sebagai berikut: }\end{array}$ \\
\hline
\end{tabular}

Tabel 3.7 Tingkat Kesejahteraan Masyarakat Mata Penambang

\begin{tabular}{cccc}
\hline No & Tingkat Kesejahteraan & Jumlah & $\begin{array}{c}\text { Persentase } \\
(\boldsymbol{\%})\end{array}$ \\
\hline 1. & Prasejahtera & 1 & $100 \%$ \\
\hline Total & 1 & $100 \%$ \\
\hline
\end{tabular}

Sumber : Data Diolah 2018 


\begin{abstract}
Dari tabel di atas dapat diketahui bahwa tingkat kesejahteraan masyarakat pekerja sebagai penambang pasir di Desa Lagasa hanya pada tahapan Prasejahtera saja. Dari tabel tersebut jumlah masyarakat yang tergolong masyarakat Prasejahtera berjumlah 1 orang dengan persentase $100 \%$.
\end{abstract} Tabel 3.8 Tingkat Kesejahteraan Masyarakat Mata Pencaharian Lain-lain

\begin{tabular}{clcc}
\hline No & Tingkat Kesejahteraan & Jumlah & $\begin{array}{c}\text { Persentase } \\
(\boldsymbol{\%})\end{array}$ \\
\hline 1. & Prasejahtera & 2 & $50 \%$ \\
\hline 2. & KS I & 2 & $50 \%$ \\
\hline \multicolumn{2}{c}{ Total } & 4 & $100 \%$
\end{tabular}

\section{Sumber : Data Diolah 2018}

Dari tabel di atas dapat diketahui bahwa tingkat kesejahteraan masyarakat pekerja lain-lain di Desa Lagasa masih berkisar pada tahapan Prasejahtera sampai KS I. Dari tabel tersebut jumlah masyarakat yang tergolong masyarakat Prasejahtera berjumlah 2 orang dengan persentase $50 \%$, dan keluarga sejahtera tahap I (KS 1) yaitu berjumlah 2 orang dengan persentase $50 \%$.

\section{PEMBAHASAN}

Berdasarkan hasil wawancara yang diperoleh dari penelitian yang dilakukan di lokasi penelitian, terlihat bahwa aktivitas keseharian dan jenis pekerjaan yang banyak dilakukan oleh masyarkat di Desa Lagasa yaitu yang pertama pekerja sebagai nelayan dengan jumlah 57 atau dengan persentasi 90,5\%. Mereka memilih bekerja sebagai nelayan sudah sejak dahulu bahkan pekerjaan ini menjadi pekerjaan pokok, selain itu masyarakat Lagasa merupakan masyarakat pesisir dimana
4.Tingkat Kesejahteraan Masyarakat Pekerja Lain-lain

Berdasarkan hasil penelitian terhadap 63 responden maka diperoleh data distribusi responden berdasarkan indikator tingkat kesejahteraan masyarakat pekerja lain-lain dapat dilihat sebagai berikut: kehidupan keseharian mereka adalah kebanyakan menagkap ikan, wajar saja kalau semua responden yang diteliti, hampir semua pekerjaannya nelayan, dan yang kedua pekerja sebagai PNS dengan jumlah 1 kepala keluarga atau dengan persentase $1,6 \%$, yang ketiga pekerja sebagai penambang dengan jumlah 1 kepala keluarga dengan persentase $1,6 \%$, dan yang ke empat pekerja lain-lain dengan jumlah 4 kepala keluarga dengan persentase $6,3 \%$.

Berdasarkan analisis data penelitian tentang tingkat kesejahteraan masyarakat berdasarka BKKBN , hasil penelitian menunjukan bahwa tingkat kesejahteraan masyarakat di Desa Lagasa masih tergolong dalam kategori yang rendah, dimana dari hasil penelitian masyarakat di Desa Lagasa tingkat kesejahteraan keluarganya masih berada pada tahapan Prasejahtera dan KS I. Hal ini dibuktikan bahwa masih banyaknya masyarakat yang tergolong tahapan Prasejahtera dengan jumlah 82,5\%, tingkat 
Jurnal Penelitian Pendidikan Geografi Volume 4 No.2 April 2019

kesejahteraan keluarga di Desa Lagasa belum bisa dikatakan baik juga karena keluarganya masih berada pada tingkat kesejahteraan tahap I (KS I) yang merupakan tingkat keluarga sejahtera yang pertama, yaitu sebanyak 17,5\%.

Keluarga yang belum bisa mencapai tahapan keluarga sejahtera atau belum bisa beranjak dari tingkat kesejahteraan tertentu dikarenakan ada indikator kesejahteraan keluarga yang masih belum bisa terpenuhi oleh keluarga tersebut, dapat dilihat pada tabel 4.1, sebagai

berikut:

Tabel 4.1. Distribusi Tingkat Kesejahteraan Keluarga Berdasarkan Indikator yang Tidak Terpenuhi

\begin{tabular}{|c|c|c|c|c|c|c|}
\hline \multirow[t]{2}{*}{ No } & \multirow{2}{*}{$\begin{array}{c}\text { Tingkat } \\
\text { Kesejahteraan }\end{array}$} & \multirow{2}{*}{$\begin{array}{c}\text { Jumlah } \\
\text { Keluarga }\end{array}$} & \multirow{2}{*}{$\begin{array}{c}\text { Indikator } \\
\text { yang Tidak } \\
\text { Terpenuhi }\end{array}$} & \multicolumn{2}{|c|}{ Jumlah } & \multirow{2}{*}{$\begin{array}{c}\text { Persentase } \\
(\%)\end{array}$} \\
\hline & & & & $\mathbf{F}$ & $\%$ & \\
\hline \multirow[t]{4}{*}{1.} & \multirow[t]{4}{*}{ Pra Sejahtera } & \multirow[t]{4}{*}{52} & Papan & 13 & $25 \%$ & \multirow[t]{4}{*}{100} \\
\hline & & & Kesehatan & 25 & $48,07 \%$ & \\
\hline & & & KB & 8 & $15,38 \%$ & \\
\hline & & & Pendidikan & 6 & $11,53 \%$ & \\
\hline \multirow[t]{5}{*}{2.} & \multirow[t]{5}{*}{ KS I } & \multirow[t]{5}{*}{11} & Agama & 3 & $27,27 \%$ & \multirow[t]{5}{*}{100} \\
\hline & & & Papan & 1 & $9,1 \%$ & \\
\hline & & & Kesehatan & 2 & $18,19 \%$ & \\
\hline & & & Penghasilan & 3 & $27,27 \%$ & \\
\hline & & & KB & 2 & $18,19 \%$ & \\
\hline
\end{tabular}

Sumber : Data Diolah 2018

Dari tabel 5.11 diatas diketahui bahwa 52 keluarga yang termagsud dalam Keluarga Pra Sejahtera, belum bisa menjadi keluarga sejahtera paling banyak karena indikator kesehatan yaitu, bila ada anggota keluarga sakit dibawa kesarana kesehatan tidak terpenuhi sebanyak 25 kepala keluarga atau sebesar 48,07\%. ini dikarenakan kebanyakan keluarga bila ada anggota keluarga yang sakit tidak langsung dibawa ke sarana kesehatan, biasanya mereka merawatnya dirumah. Jadi bila ada anggota keluarga yang sakit tidak pergi kesarana kesehatan adalah hal yang sangat jarang dilakukan.

Pada kategori KS I terdapat 11 keluarga di Desa Lagasa, pada kategori ini dikatakan tidak bisa mencapai tahap kesejahteraan KS II karena ada indikator yang tidak dapat terpenuhi yaitu indikator Agama, pada umumnya anggota keluarga melaksanakan ibadah sesuai dengan agama dan kepercayaan masing-masing tidak terpenuhi sebanyak $27,27 \%$. 


\section{KESIMPULAN}

Berdasarkan hasil penelitian dan pembahasa diketahui masyarakat di Desa Lagasa Kecamatan Duruka Kabupaten Muna, dapat disimpulkan bahwa :

1. Tingkat kesejahteraan masyarakat berdasarka BKKBN, Desa Lagasa masih tergolong dalam kategori tingkat kesejahteraan yang rendah, dimana tingkat kesejahteraan keluarganya masih berada pada tahapan Prasejahtera dan KS I. Hal ini dibuktikan bahwa masyarakat yang tergolong tahapan Prasejahtera yaitu sebanyak 52 kepala keluarga dengan jumlah persentase $82,5 \%$, dan pada tahapan keluarga sejahtera 1 (KS I) hanya berjumlah 11 orang dengan persentase 17,5\%. Dari 52 kepala keluarga yang dikategorikan Tahapan Keluarga Pra Sejahtera karena keluarga yang tidak dapat memenuhi salah satu dari 6 indikator keluarga Sejahtera I (KS I) atau indikator kebutuhan dasar keluarga, dan 11 kepala keluarga yang dikategorikan tahapan keluarga sejahtera I karena keluarga mampu memenuhi 6 indikator tahapan KS I, tetapi tidak dapat memnuhi salah satu dari 8 indikator Keluarga Sejahtera II atau indikator kebutuhan Psikologis.

2. Masyarkat di Desa Lagasa hampir sebagian besar bekerja sebagai nelayan dengan jumlah 57 kepala keluarga atau dengan persentasi $90,5 \%$, dari 57 kepala keluarga yang bekerja sebagai nelayan ada 10 kepala keluarga yang tegolong keluarga sejahtera tahap I mereka dikatakan Keluarga Sejahtera I karena mereka belum dapat memenuhi 8 indikator keluarga sejahtera II, dan 42 kepala keluarga yang bekerja sebagai nelayan ini hanya dapat dikatakan keluarga Pra Sejahtera karena mereka tidak dapat memenuhi salah satu dari 6 indikator Keluarga Sejahtera I (KS I), dan yang kedua pekerja sebagai PNS dengan jumlah 1 kepala keluarga atau dengan persentase $1,6 \%$, kepala keluarga yang bekerja sebagai PNS ini dikategorikan sebagai Keluarga Sejahtera tahap I karena merekan bisa memenuhi ke 6 indikator keluarga sejahtera I (KS I) tetapi tidak dapat memenuhi salah satu dari 8 indikator Keluarga Sejahtera Tahapan II, yang ketiga pekerja sebagai penambang dengan jumlah 1 kepala keluarga dengan persentase 1,6\%, kepala keluarga yang bekerja sebagai penambang masi dikategorikan Keluarga Pra Sejahtera karena keluarga belum bisa memenuhi salah satu dari 6 indikator Keluarga Sejahtera Tahap I, dan yang ke empat pekerja lain-lain dikategorikan masi tergolong Keluarga Pra Sejahtera karena keluarga belum bisa memenuhi salah satu dari 6 indikator Keluarga Sejahtera Tahapan I dengan jumlah 4 kepala keluarga dengan persentase $6,3 \%$.

\section{DAFTAR PUSTAKA}

Abdurracmat, I. 1984 Geografi Ekonomi, Jurusan Pendidikan Geografi. IKIP Bandung .

Acheson, James M. 1981. "Antropology of Fishing”. Annual Review of Antropology. Vol 10: 275-316.

Atikah N. 2017. Analisis Tingkat Kesejahteraan Nelayan Buruh Alat Tangkap Gill Net di Desa Sungai Buntu Kecamatan Pedes Kabupaten Karawang. Jurnal Perikanan dan Kelautan. Vol. VIII No. 2/Desember 2017 (112-117)

BKKBN, 2014. Pedoman Tata Cara Pencatatan dan Pelaporan Pendapatan Keluarga. Sumatera Utara : Badan Koordinat Keluarga Berencana Nasional. 
Jurnal Penelitian Pendidikan Geografi Volume 4 No.2 April 2019

Badan Pusat Statistik . 2009. Analisis dan Perhitungan Tingkat Kemiskinan 2009 BPS. Jakarta

Wahyu. 2007. Pergeseran Mata Pencaharian Masyarakat Desa, Skripsi : FISIP UNS. Surabaya.

Rosni, Analisis Tingkat Kesejahteraan Masyarakat Nelayan di Desa Dahari Selebar Kecamatan Talawi Kabupaten Batubara. Jurnal Geografi. Vol. 9 No. 1-2017. eISSN: 2549-7057 (57-60) 